\title{
LA PROTECCIÓN ESPECIAL Y EL INTERÉS SUPERIOR DE LA NIÑEZ MIGRANTE NO ACOMPAÑADA EN LOS PROCEDIMIENTOS MIGRATORIOS EN CENTROAMÉRICA: ANÁLISIS LEGISLATIVO ${ }^{1}$
}

\author{
SPECIAL PROTECTION AND THE BEST INTEREST OF UNACCOMPANIED \\ MIGRANT CHILDREN IN MIGRATION PROCEDURES IN CENTRAL AMERICA: \\ LEGISLATIVE ANALYSIS
}

Por Mónica M. Cárdenas Miranda ${ }^{(*)}$

\begin{abstract}
Resumen: Los movimientos migratorios en el territorio centroamericano están regulados de manera independiente en cada país, pero cuando se trata de niños, niñas y adolescentes migrantes no acompañados, es necesario regular un procedimiento especial y meticuloso para brindar atención a la niñez y adolescencia en dicha situación, por lo cual se estudian los diferentes instrumentos que cada Estado determina, para conocer las fortalezas y debilidades que existen en ese aspecto.
\end{abstract}

Palabras claves: Niñez- Adolescencia - Migración - Centroamérica - Procedimientos migratorios

\begin{abstract}
Migratory movements in Central American territory are regulated independently in each country, but when it comes to unaccompanied migrant children and adolescents, it is necessary to regulate a special and meticulous procedure to provide care for children and adolescents in such situation, Therefore, the different instruments that each State determines are studied in order to know the strengths and weaknesses that exist in this regard.
\end{abstract}

Keywords: Childhood - Adolescence - Migration - Central America - Migration Procedures

\footnotetext{
${ }^{1}$ Artículo recibido el 18 de noviembre de 2020 y aprobado para su publicación el 13 de abril de 2021.

(*) Estudiante de la Universidad Centroamericana Managua Nicaragua, C.A. Ganadora del Concurso de ensayo AUSJAL-IIDH sobre Derechos Humanos en América Latina “Xabier Gorostiaga SJ” 2020.
} 


\section{(c) (i) () $(-)$ \\ BY NC ND}

Artículo publicado bajo Licencia Creative Commons Atribución-No Comercial-Sin Derivar. C) Universidad Católica de Córdoba

DOI http://dx.doi.org/10.22529/rfd.2021(6)04 


\section{Introducción}

Los migrantes, siendo personas que abandonan su país de residencia para dirigirse a uno distinto, independientemente del motivo, se encuentran en una situación de vulnerabilidad respecto de los individuos que habitan en el lugar de destino al que se dirigen. $\mathrm{Y}$, dentro de ese conjunto, existen personas que son doblemente vulnerables. En este orden, uno de los grupos más desvalidos dentro de la categoría migratoria es, tal se evidenciará, los niños, niñas y adolescentes.

Así, particularmente los del grupo conocido como "no acompañados" se encuentran expuestos a múltiples situaciones que vulneran sus derechos, tales como: detenciones, riesgo de ser víctimas de crimen organizado o tráfico de personas, violencia, discriminación, pasar hambre y frío, no tener acceso a servicios de salud, entre otras, según plantea UNICEF (2020). Ante estas circunstancias, el Derecho debe ofrecer una solución que permita ser amparado a este sector y que su estado pueda equilibrarse a través de medidas especiales de protección y otros mecanismos que garanticen su eficacia.

A tal efecto, el 26 de diciembre de 1924 surge la Declaración de Ginebra² ${ }^{2}$ un instrumento muy breve y paradigmático porque fue el primero en la historia en otorgar a los niños y niñas una protección especial, con carácter internacional. Y, por otro lado, en 1989, la Organización de las Naciones Unidas promulgó la Convención sobre los Derechos del Niño, con un alcance universal y una regulación completa y vinculante de los derechos humanos de los niños y niñas, la cual, a su vez, introdujo el término "interés superior del niño", aunque sin definirlo, como expone Rivas (2015). Estos instrumentos significaron un hito trascendental en la historia de los derechos humanos de la niñez, pues dieron origen a los dos pilares universales de protección de la niñez que son objeto de nuestro estudio.

\footnotetext{
2 El texto traducido al español de este instrumento e información relacionada con el mismo pueden consultarse en el siguiente enlace: Bofill, A. \& Cots, J. (1999). La Declaración de Ginebra: Pequeña historia de la primera carta de los derechos de la infancia. Recuperado de https://www.savethechildren.es/sites/default/files/imce/docs/declaracion_de_ginebra_de_derech os_del_nino.pdf
} 
En este sentido, actualmente es imperativo que cada Estado garantice a niños y niñas migrantes, -sobre todo los que no están acompañados de sus padres-, diversas medidas de protección especial y se priorice sobre cualquier otro criterio de aplicación de normas jurídicas al interés superior de los niños y niñas. Por ende, el objetivo principal es analizar las legislaciones centroamericanas en aras de determinar el nivel de protección estatal en los procedimientos de atención y el estado de primacía del interés superior de los niños, niñas y adolescentes, y la tutela especial brindada, para proponer sugerencias al respecto.

\section{Los niños, niñas y adolescentes migrantes no acompañados}

Según la definición que proporciona la Organización Internacional para las Migraciones (OIM, 2017), los niños, niñas y adolescentes migrantes no acompañados son aquellos que se encuentran fuera de su país de origen, separados de ambos padres y otros parientes, y no están al cuidado de un adulto al que, por ley (ex lege) o costumbre (habitus), incumbe esa responsabilidad.

Normalmente, son numerosas y desde diversas perspectivas las causas por las que los menores de edad emigran de sus países de origen sin el acompañamiento de un familiar: problemas en el núcleo familiar, abuso familiar, una situación de extrema pobreza, o por razones ajenas a su voluntad, como la trata de personas. Sin embargo, si un niño, niña o adolescente viaja a otro país sin acompañamiento de sus padres o algún familiar o adulto que vele por su bienestar, se expone a muchísimos peligros, como se mencionó en la introducción de este ensayo, por lo cual es necesario que el Estado intervenga para proteger a la niñez y adolescencia en esa situación, sin discriminación alguna por su país de origen.

\section{Fundamentos de la protección especial a la niñez migrante} no acompañada

La protección especial no es una única acción, sino que es el término empleado para englobar todo un conjunto de acciones que el Estado tiene la obligación de emprender para garantizar el pleno ejercicio de los derechos humanos de los niños, niñas y adolescentes migrantes no acompañados. En este 
orden, expresa el Instituto Interamericano del Niño, la Niña y Adolescentes de la Organización de Estados Americanos (2011) (en adelante, IIN-OEA), esta protección se basa en los siguientes principios fundamentales inherentes al ser: interés superior del niño, no discriminación, no devolución (la persona con estatus de refugiada no debe regresar al lugar donde su vida o su libertad se pongan en peligro), unidad familiar, reunificación familiar y respeto a los derechos humanos.

Además, esa protección es especial porque variará conforme las necesidades particulares de cada niño, niña o adolescente. Así, de manera general, puede enunciarse que el fundamento jurídico de la protección especial a la niñez es la Convención sobre los Derechos del Niño (art. 3), ya que, a lo largo de su articulado, reconoce a la niñez como individuos, es decir, seres humanos independientes, no inferiores de ninguna manera a los adultos, pero que inician su vida como seres dependientes de sus padres y necesitan unos cuidados especiales.

Asimismo, al depender de un adulto (siendo los legitimados en primer lugar, sus padres) y que este se encuentre ausente, como es el caso de los niños y niñas migrantes no acompañados, corresponderá al Estado velar por sus intereses, o sea, realizar su protección, pues existe dicho compromiso en la citada Convención.

Ahora, cabe analizar las disposiciones de la Declaración Universal de los Derechos Humanos, punto de partida para explicar el siguiente fundamento de la protección especial a los niños, niñas y adolescentes. De tal modo, el art. 1 de este paradigma internacional establece el derecho humano a la igualdad que tienen los seres humanos respecto a la dignidad y sus derechos; y el art. 7, que es la esencia del principio y derecho humano a la igualdad ante la ley y de protección contra toda discriminación. Adicionalmente, el art. 25, num. 2, determina que la maternidad y la infancia tienen derecho a cuidados y asistencia especiales y protección social.

Entonces, habida consideración de que la infancia tiene derecho a cuidados y asistencia especiales (protección especial) y todos los seres humanos son iguales y tienen los mismos derechos, significa que los niños, niñas y adolescentes migrantes no acompañados no deben ser discriminados bajo ninguna circunstancia y el 
Estado debe otorgar idénticas garantías y derechos que a todos los demás niños: salud, educación, alimentación, recreación, derecho a familia, etc.

Cada país regula también, tanto la protección especial a la niñez como el derecho a la igualdad, en sus ordenamientos jurídicos. Por ejemplo, Guatemala regula la igualdad en el art. 4 de la Constitución Política, y en el art. 51 la protección a los menores de edad (salud física, mental, moral, derecho a la salud, alimentación, educación, seguridad y previsión social); en la Constitución Política de El Salvador se contempla la igualdad en el art. 3, y en los arts. 34 y 35 se dispone el derecho de los niños y niñas (con el término "menor") de ser protegido por el Estado para su desarrollo integral y sobre su salud física, mental, moral, derecho a la educación y asistencia; la norma suprema de Honduras instaura la igualdad en el art. 60 y 61, y la protección especial a la niñez en el art. 120 (aunque son anticuadas estas regulaciones)3; en la Constitución Política de Nicaragua la igualdad de todas las personas ante la ley se erige en el art. 27, mientras que la protección especial en el art. 71; y, por último, en la Constitución de Costa Rica4, la igualdad se dispone en el art. 33, y la protección especial a los menores de edad en los arts. 51 y 55 .

\section{Fundamento jurídico del principio del interés superior de la niñez migrante no acompañada}

En la Convención sobre los Derechos del Niño se determina (art. 3, num. 1):

En todas las medidas concernientes a los niños que tomen las instituciones públicas o privadas de bienestar social, los tribunales, las autoridades administrativas o los órganos legislativos, una consideración primordial a la que se atenderá será el interés superior del niño.

\footnotetext{
3 El art. 60 de la Constitución Política hondureña menciona que "todos los hombres nacen libres e iguales en derechos [...], lo cual, si bien se entiende que se refiere a "hombre" en su acepción humana, englobando hombres y mujeres, es un enunciado que invisibiliza a la mujer. Y, de igual manera, el art. 120 dice que "los menores de edad, deficientes física o mentalmente, los de conducta irregular, los huérfanos y los abandonados están sometidos a una legislación especial de rehabilitación, vigilancia y protección según sea el caso", por lo que es notorio que utiliza un lenguaje despectivo y que en la actualidad se considera inadecuado. Es necesaria una reforma para actualizar el lenguaje empleado en la norma.

4 Se revisó la edición compilada por Vinicio Piedra Quesada (2017).
} 
Esta norma es trascendental, puesto que se deriva la obligación que tienen los Estados, entre ellos los que son objeto de análisis, de priorizar el interés superior de los niños, niñas y adolescentes sobre cualquier otra circunstancia, por lo cual todas las legislaciones deberán adaptarse a esta exigencia, así también sus procedimientos migratorios, administrativos, judiciales y demás. Implica, a su vez, necesariamente, que los niños, niñas y adolescentes deben ser escuchados cuando se trate de cualquier decisión que los afecte, teniendo en cuenta su capacidad progresiva. Por tanto, un procedimiento de atención garantista para la niñez migrante tomará siempre en consideración el criterio del niño, niña o adolescente.

Según Cillero Bruñol (2007) el interés superior de la niñez tiene una triple función insoslayable: a) es una garantía, pues toda decisión concerniente a la niñez y adolescencia debe considerar sus derechos y obliga al legislador y a las autoridades e instituciones públicas y privadas (y a los padres); b) es una norma de interpretación y/o de resolución de conflictos jurídicos; c) es una orientación o directriz política para la formulación de políticas públicas para la infancia.

Por consiguiente, siendo que las autoridades (el Estado y sus instituciones subordinadas) tienen la obligación de velar por la protección del interés superior de la niñez y adolescencia, es claro que las autoridades migratorias no son la excepción y también deben cumplir con dicho deber. $\mathrm{Y}$ también deben elaborarse políticas públicas sociales encaminadas a erradicar los problemas actuales, que parten del punto legislativo, puesto que las autoridades actúan según lo que las leyes establezcan. Se profundiza en este aspecto más adelante.

En esta línea, señala Ortega Velázquez (2015): “[la niñez es niñez ante todo], su calidad de extranjero o, aún más, de migrante irregular, es algo secundario que no debe obstaculizar ninguna de las garantías previstas para quienes forman parte de un grupo social muy vulnerable". Y es muy necesario que se brinde a los niños y niñas migrantes no acompañados una protección especial reforzada, fundada, a su vez, en el principio de interés superior de la niñez, al que todos los Estados están comprometidos a situar en una posición de primacía respecto a cualquier otro interés individual o colectivo. 
Así, pues, puede comprobarse la presencia de este principio en los ordenamientos jurídicos que son objeto de estudio, observando los preceptos normativos en que se encuentra regulado: En Guatemala, el interés superior de la niñez "y la familia" se regula en el art. 5 del Decreto No. 27-2003: Ley de Protección Integral de la Niñez y la Adolescencia; en El Salvador, la Ley (de nombre igual a la anterior, Decreto No. 839) lo estipula en su art. 12; Honduras, en su Código de la Niñez y la Adolescencia (CNA) (Decreto 35-2013), en su art. 5 y art. 180.b lo consagra como principio rector; Nicaragua, país que también tiene un Código de la materia (Ley No. 287), define al interés superior de la niñez y la adolescencia en el art. 10 y en el art. 9 lo instituye como principio primordial; y, por último, Costa Rica, en su Código de la Niñez y la Adolescencia (Ley No. 7739), protege el interés superior de la niñez en el art. 4, como políticas estatales, y en el art. 5 lo extiende.

En este sentido, se corrobora el compromiso adoptado por los Estados para detallar en sus legislaciones migratorias un protocolo minucioso para proteger a los menores de edad en situación migratoria que no se encuentran acompañados, y se reafirma con sus compromisos internacionales, como se explica a continuación.

\section{Breve acercamiento al marco jurídico internacional en materia de protección a la niñez migrante no acompañada}

En primer lugar, es meritorio mencionar la Convención sobre los Derechos del Niño, que, según el IIN-OEA (2016) es donde se plantean los principios fundamentales que rigen la protección de sus derechos. Y, en conjunto, se genera la obligación a los Estados partes de proteger a los niños, niñas y adolescentes migrantes no acompañados de la violencia y la explotación, además de garantizar su acceso a la salud, nivel de vida adecuado, educación, ocio y recreación. Otro punto importante es la obligación estatal de adopción de medidas legislativas, administrativas, sociales y educativos para proteger a estos niños y niñas. Todo bajo la garantía del debido proceso y demás prerrogativas constitucionales. 
Luego, la Observación General No. 6 "Trato de los menores no acompañados y separados de su familia fuera de su país de origen”, del Comité de los Derechos del Niño (2005), que está centrada en exponer las dificultades afrontadas por la niñez y adolescencia migrante no acompañada y sugerir las acciones que los Estados pueden emprender a nivel legislativo, administrativo y judicial.

Igualmente, la Convención Americana sobre Derechos Humanos, que determina en su art. 19 la "protección a los derechos del niño", pero no hay que olvidar que estos son derechos especiales, adicionales a sus derechos humanos, entre los cuales destaca la igualdad ante la ley, que es trascendental fundamento para establecer que todo niño o niña tiene derechos humanos, aunque se encuentre fuera de su país de origen.

También es válido considerar el Memorándum de Entendimiento entre los gobiernos de los Estados Unidos Mexicanos, de la República de El Salvador, de la República de Guatemala, de la República de Honduras y de la República de Nicaragua para la repatriación digna, ordenada, ágil, y segura de los nacionales centroamericanos migrantes vía terrestre (2006), orientado en la Conferencia Regional sobre Migración (1996), en el cual se señaló el fundamento para el retorno digno, ordenado y seguro de los migrantes originarios de dichos países. Y, con esa misma finalidad, los Lineamientos Generales para la Atención de Niños, Niñas y Adolescentes Migrantes No Acompañados en casos de Repatriación (2009), aunque sin especificar cuestiones como el transporte o los horarios (IIN-OEA).

En este orden de ideas, la Declaración Extraordinaria de Managua (2014) enfatiza en el peligro de la migración, la amenaza de los grupos dedicados a la trata de personas, y en ese sentido se invita a los Estados a trabajar de forma conjunta (IIN-OEA). Y, finalmente, la Declaración de Montevideo y Compromiso de Montevideo sobre Migraciones y Desarrollo (2006), que, de igual manera, insta a crear programas de cooperación para prevenir y combatir la trata de personas y proteger principalmente a la niñez migrante. 
Expuestos los compromisos internacionales y valorado su alcance $\mathrm{y}$ trascendencia, conviene ahora verificar su cumplimiento en cada país de Centroamérica, analizando los procedimientos de atención en la materia.

\section{Análisis legislativo de la protección especial y supremacía del interés superior en los procedimientos de atención a la niñez migrante no acompañada en Centroamérica}

Para efectos de este ensayo, la existencia de un procedimiento específico de atención a la niñez migrante no acompañada constituye una forma de protección especial, pero es necesario analizar las legislaciones migratorias de cada país de Centroamérica, en búsqueda de la regulación de este y verificar el respeto al interés superior de la niñez que, tal se ha explicado, es la piedra angular de sus derechos.

\subsection{Guatemala}

En primer lugar, el cuerpo normativo que regula el flujo migratorio en Guatemala es el Decreto número 44-2016, llamado Código de Migración. En esta norma jurídica, en la materia objeto de análisis (niñez migrante no acompañada), los procedimientos se rigen por los principios de: interés superior del niño, no discriminación, unidad familiar y derecho a la reunificación familiar, comunicación y preservación de relaciones personales y contactos directos entre los niños y padres, no violencia y trato digno, protección y seguridad, legalidad y debido proceso, confidencialidad de registros y protección de la vida privada, especialización del personal a cargo de la gestión migratoria de la niñez migrante, principio de "no devolución cuando está en riesgo la integridad personal", derecho a la vida, supervivencia y desarrollo y derecho a expresar libremente su opinión (art. 170).

Este Código, además, garantiza a la niñez migrante no acompañada los siguientes derechos: atención en programas especializados en casas especiales autorizadas por el Estado (art. 11); protección contra el trabajo infantil (art. 23, literal g); acceso a procedimientos que reconozcan sus necesidades especiales y pleno desarrollo de su personalidad (art. 38); a permanecer en comunicación y 
contacto familiar (art. 19). También, en caso de que los niños o niñas estén siendo víctimas de violencia sexual, explotación y trata de personas, ofrece a las víctimas una atención especializada mediante órganos especializados (arts. 39 y 49).

Es relevante y necesario mencionar que en Guatemala se niega el egreso de los niños, niñas y adolescentes que viajen solos o en compañía de un tercero sin autorización de sus padres, tutores, o quien ejerza la autoridad parental (arts. 61 y 89). Incluso, no es permitida la obtención del pasaporte sin esta autorización.

Ahora bien, el procedimiento de atención inicia en la Secretaría de Bienestar Social de la Presidencia de la República, que tiene el deber legal de priorizar la acogida del menor de edad con familiares que residan en el país, pero si no es posible, se puede recurrir al procedimiento que especifica el Reglamento del Código (Acuerdo de Autoridad Migratoria Nacional No. 7-2019, art. 173).

Así, como primer paso, la Secretaría de Bienestar Social de la Presidencia de la República identifica la existencia de un niño, niña o adolescente migrante no acompañado, susceptible de reconocimiento de refugio, asilo $\mathrm{u}$ otra medida de protección internacional o reunificación familiar y lo comunica a la Subdirección de Atención y Protección de Derechos Fundamentales de los Migrantes.

Posteriormente, se informa al niño, niña o adolescente en cuestión de sus derechos dentro del procedimiento y los servicios a los que puede acceder, para luego entrevistarle conforme con el procedimiento específico para solicitar refugio, con la finalidad de establecer su identidad, país de origen, situación migratoria, paradero de sus familiares y necesidades especiales de protección, lo cual también garantiza que se le reconozcan los derechos previstos en la Constitución Política de la República de Guatemala (art. 45 del Código de Migración).

También se coordinará con el consulado del país de origen del menor de edad la solicitud de búsqueda de sus familiares adultos, salvo por solicitud formal de refugio. Todo este procedimiento se expresa en el art. 97 del Reglamento General del Código de Migración. 
Además, es importante señalar que Guatemala cuenta con un protocolo de atención y protección para los niños, niñas y adolescentes migrantes no acompañados, que es una hoja de ruta acordada entre instituciones de Guatemala y México repatriados desde este último, donde se detecta al niño o niña migrante en dicha situación, se le conduce a una estación migratoria cercana y recibe atención de un Oficial de Protección de Infancia que le es asignado, para su posterior entrevista para conocer su identidad, nacionalidad, motivo de la separación, estado de salud, si requiere protección internacional y si fue víctima de trata de personas $\mathrm{y}$, dependiendo de los resultados, se prosigue. Se avisa a la autoridad consular de Guatemala sobre la situación del niño o niña para que contribuyan con el procedimiento, y se realizan las gestiones para localizar a los familiares del niño o niña y proceder a su repatriación (IIN-OEA, 2011).

Y, conjuntamente, se establece el Protocolo Nacional para la Recepción y Atención de Niñez y Adolescencia Migrante, en el cual se fija la ruta de atención para la repatriación de las niñas, niños y adolescentes migrantes no acompañados desde México por vía terrestre, vía aérea, y también una ruta de atención de unidades familiares migrantes por vía aérea desde México y Estados Unidos (Gobierno de la República de Guatemala, 2017).

\subsection{El Salvador}

Siguiendo la línea anterior, en el caso de El Salvador, las regulaciones migratorias se encuentran en la Ley Especial de Migración y Extranjería (Decreto No. 286). Esta, igualmente, declara que en ningún caso se inadmitirán a las "personas menores de dieciocho años de edad no acompañadas" -como se les llama a los niños, niñas y adolescentes en dicha norma- y se incluye a personas que, según la Dirección General de Migración, se encuentren en condiciones de vulnerabilidad (art. 42).

Conjuntamente, una niña, niño o adolescente podrá solicitar residencia mediante la gestión de un tercero, siempre que exista un poder especial que haya emitido quien ejerza su autoridad parental o representación legal (art. 61). En este orden, es preciso señalar que en caso de que no sea posible lo anterior, estos 
menores de edad pueden ser representados por la Procuraduría General de la República de El Salvador para la expedición de documentos de viaje (art. 70) y en todo caso en que existan intereses contrapuestos (art. 322 parte in fine).

Asimismo, se puede conceder a una niña, niño o adolescente no acompañado con discapacidad o en situación de desamparo la llamada "residencia por razones humanitarias" (art. 181 del Reglamento de la Ley Especial de Migración y Extranjería: Decreto No. 35), e incluso la residencia definitiva, por sí mismos con el cumplimiento de unos requisitos, destacando el literal e, al añadir otros criterios en caso de que el niño o niña sea mayor de 14 años y trabaje (art. 194, Reglamento). Es interesante, sobre este último aspecto, que incluso se llegan a reconocer derechos laborales a los menores de edad no acompañados con edad para laborar, sin discriminarles por su situación migratoria.

En este orden de ideas, para el procedimiento de atención en El Salvador, serán las autoridades migratorias quienes se encargarán de informar de la admisión al país de niños, niñas y adolescentes no acompañados y, a su vez, remitirán el caso al Consejo Nacional de la Niñez y la Adolescencia, Juntas de Protección y Procuraduría General de la República, teniendo en consideración el principio de interés superior de la niña, niño y adolescente (art. 43 de la Ley).

La Junta de Protección de la Niñez y la Adolescencia, teniendo en conocimiento al menor de edad no acompañado, debe dictar la medida de protección administrativa que corresponda y resolver sobre su permanencia en el país o repatriación y, de ser procedente, remitir al Juzgado Especializado de la Niñez y la Adolescencia. También informará a la Procuraduría General de la República. Estas instituciones pueden solicitar que se expida el documento migratorio, se otorgue un estatus migratorio, se dé un trato preferencial en puestos para tránsito internacional de personas y se brinde medidas de apoyo (art. 305).

En todo este procedimiento se debe informar al niño, niña o adolescente de sus derechos, brindarle alojamiento considerando sus necesidades particulares o condición de vulnerabilidad, atender al principio de unidad familiar, abrir un expediente administrativo incluyendo un registro fotográfico, notificar a la 
embajada del país de origen, garantizar el acceso a la educación y acceso a la salud, así como involucrar a la Procuraduría General de la República (art. 306).

Así también, El Salvador diseñó su Protocolo de Protección y Atención de Niñez y Adolescencia Migrante Salvadoreña, con el apoyo de la Organización Internacional para las Migraciones, basado en su legislación nacional, donde el procedimiento antes resumido es explicado de manera mucho más amplia y específica, el cual fue elaborado por el Consejo Nacional de la Niñez y la Adolescencia. Y también la Cartilla de Ruta de Atención y Protección a Niñez y Adolescencia Migrante, en la cual se detalla que con la representación consular inicia el proceso para identificar y averiguar el origen del niño o niña migrante no acompañado, prosiguiendo con una entrevista preliminar y siempre con la asistencia consular durante un procedimiento minucioso detallado en ese documento.

\subsection{Honduras}

En este punto del análisis ocurre un giro, puesto que en la Ley de Migración y Extranjería de Honduras (Decreto No. 208/2003) no existe ningún trato especial ni procedimiento de tratamiento específico para las niñas y niños migrantes no acompañados. La regulación más aproximada al tema está referida a los menores de edad con discapacidad, y se expresa que solo puede permitírseles la entrada al país si lo hacen bajo el cuidado de personas nacionales o extranjeras que, a juicio de la Dirección General de Migración y Extranjería, sean aptas para ello (art. 81).

Así también, podrían obtener la residencia los "hijos menores" 5 de rentistas, pensionados e inversionistas (art. 21). Ahora bien, en el Reglamento de la ley citada

\footnotetext{
5 En el análisis de estas normas fue notorio que también es preciso actualizar el lenguaje jurídico empleado en la norma, siendo que en Honduras sigue llamándose "menor" a todo niño, niña o adolescente, lo cual es un término no aconsejable para referirse a ellos, ya que, como explica Ortega Velázquez (2015), antes de la aprobación de la Convención sobre los derechos del niño, se tomaba como base a la doctrina de la situación irregular, bajo la cual se definía como "menores" a los sujetos que eran ajenos al vocablo "niños", por haber sido abandonados, víctimas de abusos o maltratos o haber sido infractores de la ley penal. Es por ello que es trascendental que en futuras reformas o, quizás, en una nueva ley que regule las situaciones migratorias, además de incluir un procedimiento de atención para los niños, niñas y adolescentes migrantes no acompañados, se les deje de denominar como "menores", ya que este es un término peyorativo e incluso discriminatorio, nacido de un historial de distinciones y separaciones de los niños y niñas en categorías, donde unos eran superiores a otros, lo cual, a todas luces, es incorrecto y violatorio de sus derechos.
} 
(Acuerdo No. 018-2004) se observa que para la obtención del pasaporte es requisito la compañía de sus padres, o quien ejerza la "patria potestad" (art. 97).

No obstante, es destacable que Honduras, si bien tiene una legislación migratoria relativamente desactualizada, sí cuenta con una normativa especializada para tutelar a la niñez migrante en general, que es el Protocolo de Protección Inmediata, Repatriación, Recepción y Seguimiento de Niñas y Niños Migrantes, donde se considera la situación de vulnerabilidad de estos niños y niñas, y se consideran las observaciones realizadas por el Comité de los derechos del niño al Estado de Honduras, y se delega a la Dirección de Niñez, Adolescencia y Familia la coordinación de acciones de repatriación, protección, reinserción, seguimiento y acompañamiento para la niñez migrante no acompañada, y a la Dirección Nacional de Transporte para coordinarse y monitorear a las unidades de transporte terrestre que los conduzcan a sus familiares "de México", específicamente.

\subsection{Nicaragua}

En el caso de Nicaragua, la norma jurídica que regula el flujo migratorio de forma general es la Ley General de Migración y Extranjería (Ley No. 761), en la cual no se regula ningún procedimiento de atención ni medida de protección alguna a favor de los niños y niñas migrantes no acompañados, tanto en la Ley como en su Reglamento (Decreto Ejecutivo No. 31-2012).

Puede decirse, incluso, que el motivo es que la legislación requiere actualizarse según el contexto internacional sobre la migración de menores de edad, como lo han hecho los demás países de Centroamérica, pues en las normas nicaragüenses respectivas ni siquiera se considera dicha problemática.

Tampoco existe ningún protocolo de atención a niñez migrante por aparte, y esto se confirma en el informe que proporcionó Aldeas SOS Nicaragua para el informe del Consejo de Derechos Humanos de las Naciones Unidas en 2015, pues este organismo expresó considerar insuficientes la efectividad de la ley y las políticas migratorias existentes. 
Esto se explica en que no basta con la ratificación de instrumentos internacionales, que existan leyes que protegen a los niños y niñas en el propio país, o que la Constitución Política de Nicaragua (art. 27) proclame la igualdad de todas las personas (incluyendo extranjeros) ante la ley, si hay un enorme vacío legal respecto al procedimiento que las autoridades migratorias tomarían en caso de que ingrese un niño, niña o adolescente migrante no acompañado, y ni siquiera se cuenta en el la legislación nicaragüense con una definición para tal efecto, por lo cual las autoridades no se encuentran debidamente preparadas para atender ese tipo de situaciones amparadas en la legalidad, por lo cual no hay certeza objetiva de que a esos niños y niñas se les respeten sus derechos, se les brinde la protección especial que ameritan y prime su interés superior en todo momento.

\subsection{Costa Rica}

En Costa Rica, la materia migratoria es expuesta, por una parte, en la Ley de Migración y Extranjería (Ley No. 8487) y su Reglamento (Decreto No. 37112-GOB), $\mathrm{y}$, asimismo, en instrumentos adyacentes.

Continuando con la línea argumental, la manera más sencilla de otorgar la permanencia a una persona migrante menor de edad es que esta sea hija o hijo de una persona extranjera con permanencia autorizada mediante las categorías migratorias de residentes permanentes o temporales (art. 100 de la Ley), o siendo hijo o hija de personas comprendidas en subcategorías como inversionistas, pensionados, científicos, deportistas, entre otros (art. 75, de residencia temporal).

Ahora, estudiando el Reglamento de la Ley de Migración y Extranjería, se encontró que en su art. $7 \mathrm{y}$ art. 125 que existe la posibilidad de tramitar una solicitud de estadía y permanencia legal de una "persona extranjera menor de edad no acompañada”, gestionada por un tercero, siempre que presente un poder especial emitido por quien o quienes ejerzan la autoridad parental.

Por otro lado, el art. 141 del Reglamento determina que podría otorgarse una categoría especial, al no cumplir con los requisitos de una solicitud de regularización, siguiendo el procedimiento especial establecido en el llamado "Protocolo de Regularización de Permanencia de las Personas Menores de Edad". 
Cabe señalar también que Costa Rica elaboró el Protocolo para la atención y protección de las personas menores de edad extranjeras no acompañadas o separadas, fuera de su país de origen, en el año 2012, donde se fija el procedimiento que sigue la Dirección General de Migración y Extranjería y el Patronato Nacional de la Infancia y la Dirección General de Migración y Extranjería, el cual es similar a los que se han ido explicando, cuyo primer paso es identificar a la persona menor de edad no acompañada o separada, como tal, para, posteriormente, entrevistarla para recabar información y coordinar con el Patronato el traslado, para lo cual la Dirección General de Migración y Extranjería expedirá un documento migratorio, permiso de salida y trato preferencial en los puestos de tránsito internacional.

Como expresa el IIN-OEA (2016), es loable que el Patronato se coordina con el Ministerio de Educación Pública, para que a estos niños y niñas se le garantice el acceso a la educación mientras dure el procedimiento para su reintegración, reasentamiento o retorno. Dependiendo de la decisión, considerando el interés superior de la niñez, en el caso de retorno se aplica el Protocolo para la Repatriación de Personas Menores de Edad, y si se decide su permanencia en el país se aplica lo que se ha explicado sobre una categoría especial, con el Protocolo para la Regularización de la Permanencia de Personas Menores de Edad Extranjeras.

\section{Sugerencia de política pública o proyecto legislativo: Protocolo de atención a la niñez y adolescencia migrante no acompañada (Nicaragua)}

Ahora, se ha logrado evidenciar que a nivel centroamericano existen grandes avances en la protección especial y el interés superior de los niños, niñas y adolescentes migrantes no acompañados, puesto que cuatro de los cinco países que se han analizado cuentan con al menos un protocolo de atención con alcance nacional, o bilateral, como en el caso de Guatemala y México. 
Empero, no solo es necesaria, sino de carácter urgente la implementación por parte del Estado de Nicaragua de un protocolo de atención para la niñez y adolescencia migrante no acompañada, con la coordinación entre las autoridades migratorias (Dirección General de Migración y Extranjería) y el Ministerio de Familia, Adolescencia y Niñez, en el cual se detallen los procedimientos específicos, considerando las distintas circunstancias que se pueden presentar, para atender a estos niños, niñas y adolescentes con plena garantía de sus derechos humanos, sobre todo la educación, alimentación y unidad familiar, con una protección especial y con la primacía de su interés superior. Para ello, Nicaragua puede tomar como modelo la estructura y contenido de los protocolos centroamericanos ya existentes y adaptarlo al contexto sociocultural y jurídico nacional.

Todo, por supuesto, con fundamento en los compromisos internacionales que ya han sido analizados, en la Constitución Política de Nicaragua (art. 27), que proclama la igualdad de amparo legal y de derechos entre nacionales y extranjeros, en la protección especial que demanda el Código de la Niñez y la Adolescencia nicaragüense, y el interés superior de los niños, niñas y adolescentes (art.9, CNA).

$\mathrm{Y}$, conjuntamente, un punto importante al que prestar atención es el control de los llamados "puntos ciegos", ya que es el método de ingreso comúnmente usado para evadir los controles migratorios de forma irregular, como mencionan Aldeas SOS Nicaragua, y podría ser utilizado por muchos niños, niñas y adolescentes que viajen en caravanas de migrantes, exponiéndose a múltiples riesgos, como el abuso, la explotación laboral, violación, hambre, frío, etc., o bien, de ser víctimas de trata, serían ingresados por dicho medio, por lo que el protocolo puede ser un instrumento oportuno para mejorar la efectividad de las actuaciones de las autoridades ante dichas situaciones.

\section{Conclusiones}

Los niños, niñas y adolescentes migrantes no acompañados son un sector vulnerable y expuesto a múltiples riesgos, por lo que requieren una protección reforzada, al pertenecer a tres categorías vulnerables de su denominación. Los 
Estados deben garantizar sus derechos humanos y los que especialmente les corresponden por su condición migratoria y de niñez, mediante procedimientos migratorios garantistas, donde su interés superior sea la prioridad siempre, sin establecer ninguna distinción por su país de origen, por su condición de migrantes o por no estar acompañados por sus padres o cualquier otra persona responsable, sino lo contrario: otorgarles una protección reforzada por esos motivos.

Como se observa en este ensayo, los países de Centroamérica estipulan en sus legislaciones la igualdad como base sobre la cual se erige la protección de los derechos humanos de la niñez y adolescencia migrante no acompañada, pese a no encontrarse en su país de origen, ya que deben ser tratados sin discriminación.

Ahora bien, respecto a los procedimientos migratorios de los países centroamericanos, es loable que Guatemala dispone de un Código de Migración que contempla de forma detallada el procedimiento migratorio para la niñez migrante no acompañada, y además otros tres protocolos para distintas situaciones.

Lo mismo puede decirse de El Salvador, que en su Ley Especial de Migración y Extranjería regula un procedimiento minucioso y protector, en el cual es remarcable el acompañamiento estatal brindado a la niñez migrante no acompañada, donde incluso hay un organismo estatal que puede hacer las veces de representante legal en defecto de este, y el reconocimiento de derechos laborales a los adolescentes migrantes en edad laboral, y adicionalmente tener un protocolo especializado, con lenguaje y diseño comprensibles.

También es loable el trabajo de Honduras, pues cuenta con un protocolo especializado, que suple los vacíos de su legislación migratoria, pese a que esta necesita ser actualizada al contexto actual de derechos humanos.

De igual manera, Costa Rica, pese a no tener una legislación amplia en el tema, existen dos protocolos que se pueden emplear, dependiendo si el niño o niña es retornado o permanece en el país, con la garantía de cumplimiento de sus derechos, entre ellos la educación. 
No obstante, en este punto se reafirma la urgencia de que Nicaragua implemente, como mínimo, un protocolo nacional que garantice los derechos de los niños, niñas y adolescentes migrantes no acompañados, pues es el único país centroamericano que no ha tomado ninguna acción al respecto, ni ha acatado las recomendaciones de organismos internacionales ni cumplido los compromisos que ha adoptado, ya que no basta con las normas aisladas, que no detallan ningún procedimiento ni determinan ninguna obligación para las autoridades. Por ello, se reitera la sugerencia de que Nicaragua elabore su propio marco normativo que regule un procedimiento claro y minucioso que proteja a la niñez migrante desde su ingreso en el territorio nacional hasta que se decida sobre su retorno o permanencia, según lo que resulte más conveniente, en observancia a su interés superior.

Finalmente, por supuesto, cabe señalar que aun con la existencia de protocolos y de conjuntos de normas jurídicas que, al menos en teoría, protejan a la niñez migrante no acompañada y determinen un procedimiento claro para su atención en el ámbito migratorio, no es suficiente para que sus derechos se materialicen en la práctica. En contraposición, se requiere el ineludible compromiso de cada Estado, mediante las autoridades migratorias, para hacer cumplir las disposiciones normativas con responsabilidad, otorgando al interés superior de la niñez la primacía que le corresponde, y reforzando la protección especial a dicho sector, que, como fue expresado antes, es doblemente vulnerable, sin omitir que los niños, niñas y adolescentes migrantes no acompañados deben gozar, en cualquier circunstancia y lugar del mundo, de todos los derechos que les son reconocidos a la niñez y la adolescencia. 


\section{LA PROTECCIÓN ESPECIAL Y EL INTERÉS SUPERIOR DE LA NIÑEZ MIGRANTE NO ACOMPAÑNADA EN LOS \\ PROCEDIMIENTOS MIGRATORIOS EN CENTROAMÉRICA: ANÁLISIS LEGISLATIVO}

\section{Lista de referencias}

Acuerdo de Autoridad Migratoria Nacional No. 7-2019. Reglamento General del Código de Migración. Publicado en Diario de Centroamérica No. 40,158 del 17 de enero de 2020. Guatemala.

Acuerdo No. 018-2004. Reglamento de la Ley de Migración y Extranjería. Publicado en La Gaceta el o3 de mayo de 2004. Honduras.

Aldeas Infantiles SOS Nicaragua. (2015). Los niños y adolescentes migrantes no acompañados y los derechos humanos: Cuestionario para las Organizaciones No Gubernamentales. Recuperado de https://www.ohchr.org/Documents/HRBodies/HRCouncil/AdvisoryCom /Migrant/AldeasInfantilesSOSNicaragua.doc

Cillero Bruñol, M. (2007). El interés superior del niño en el marco de la Convención Internacional sobre los Derechos del Niño. Justicia y Derechos del Niño (UNICEF), (9). Santiago. 134-137.

Consejo Nacional de la Niñez y la Adolescencia del Gobierno de El Salvador.

(s.f.). Protocolo de Protección y Atención de Niñez y Adolescencia Migrante Salvadoreña. Recuperado de https://www.transparencia.gob.sv/institutions/conna/documents/26949 2/download

Consejo Nacional de la Niñez y la Adolescencia del Gobierno de El Salvador. (s.f.). Cartilla de Ruta de Atención y Protección a Niñez y Adolescencia Migrante. Recuperado de

https://www.transparencia.gob.sv/institutions/conna/documents/142492/down load

Constitución Política de Guatemala. 31 de mayo de 1985. Guatemala. 


\section{LA PROTECCIÓN ESPECIAL Y EL INTERÉS SUPERIOR DE LA NIÑEZ MIGRANTE NO ACOMPAÑNADA EN LOS \\ PROCEDIMIENTOS MIGRATORIOS EN CENTROAMÉRICA: ANÁLISIS LEGISLATIVO}

Constitución Política de la República de Nicaragua y sus reformas. Publicada en

La Gaceta Diario Oficial No. 32 del 18 de febrero de 2014. Nicaragua.

Convención Americana sobre Derechos Humanos. 22 de noviembre de 1969. Recuperado de https://www.oas.org/dil/esp/tratados_b32_convencion_americana_sobre_derechos_humanos.htm

Convención sobre los derechos del niño. 20 de noviembre de 1989. Recuperado de https://www.un.org/es/events/childrenday/pdf/derechos.pdf

Declaración de Montevideo y Compromiso de Montevideo sobre Migraciones y Desarrollo. 5 de noviembre de 2006. Recuperado de https://oiss.org/wpcontent/uploads/200o/o1/Declaracion-Montevideo-Con-ComunicadosEspeciales.pdf

Declaración Extraordinaria de Managua. 9 de julio de 2004. Recuperado de http://www.oas.org/juridico/spanish/corr_managua_declsp.doc

Decreto Ejecutivo No. 31-2012. Reglamento a la Ley No. 761, Ley General de Migración y Extranjería. Publicado en La Gaceta Diario Oficial No. 184, 185, 186 del 27, 28 de septiembre y 1 de octubre de 2012. Nicaragua.

Decreto No. 208/2003. Ley de Migración y Extranjería. Publicado en La Gaceta del 03 de marzo de 2004. Honduras.

Decreto No. 27-2003. Ley de Protección Integral de la Niñez y Adolescencia. Publicado en Diario de Centroamérica No. 13 del 18 de julio de 2003. Guatemala.

Decreto No. 286. Ley Especial de Migración y Extranjería. Publicado en Diario Oficial No. 75 del 25 de abril de 2019. El Salvador. 


\section{LA PROTECCIÓN ESPECIAL Y EL INTERÉS SUPERIOR DE LA NIÑEZ MIGRANTE NO ACOMPAÑNADA EN LOS \\ PROCEDIMIENTOS MIGRATORIOS EN CENTROAMÉRICA: ANÁLISIS LEGISLATIVO}

Decreto No. 35. Reglamento de la Ley Especial de Migración y Extranjería. Publicado en Diario Oficial No. 96 del 28 de mayo de 2019. El Salvador.

Decreto No. 35-2013. Código de la Niñez y de la Adolescencia. Publicado en La Gaceta del No. 33-222 del o6 de septiembre de 2013. Honduras.

Decreto No. 37112-GOB. Reglamento de Extranjería. Publicado en La Gaceta Diario Oficial No. 95 del 17 de mayo de 2012. Costa Rica.

Decreto No. 38. Constitución de la República de El Salvador. 15 de diciembre de 1983. El Salvador.

Decreto No. 44-2016. Código de Migración. Publicado en Diario de Centroamérica No. 70 del 18 de octubre de 2016. Guatemala.

Decreto No. 839. Ley de Protección Integral de la Niñez y Adolescencia.

Publicada en el Diario Oficial No. 68 del 16 de abril de 2009. El Salvador.

Dirección de Niñez, Adolescencia y Familia del Gobierno de Honduras. (s.f.).

Protocolo de Protección Inmediata, Repatriación y Seguimiento de Niñas y Niños migrantes. Recuperado de https://tbinternet.ohchr.org/Treaties/CMW/Shared\%2oDocuments/HN D/INT_CMW_ADR_HND_23865_S.pdf

Dirección General de Migración y Extranjería \& Patronato Nacional de la Infancia. (2012). Protocolo para la atención y protección de las personas menores de edad extranjeras no acompañadas o separadas, fuera de su país de origen. Costa Rica. Recuperado de https://pani.go.cr/descargas/conatt/614-protocolo-para-la-atencion-yproteccion-de-las-personas-menores-de-edad-extranjeras-noacompanadas-o-separadas-fuera-de-su-pais-de-origen/file 


\section{LA PROTECCIÓN ESPECIAL Y EL INTERÉS SUPERIOR DE LA NIÑEZ MIGRANTE NO ACOMPAÑNADA EN LOS \\ PROCEDIMIENTOS MIGRATORIOS EN CENTROAMÉRICA: ANÁLISIS LEGISLATIVO}

Gobierno de la República de Guatemala. (2017). Protocolo Nacional para la Recepción y Atención de Niñez y Adolescencia Migrante. Recuperado de https://www.refworld.org.es/pdfid/5coo2c1c4.pdf

Instituto Interamericano del Niño, la Niña y Adolescentes de la Organización de Estados Americanos. (2011). Atención y protección de los Derechos de Niñas, Niños y Adolescentes. Recuperado de http://www.iin.oea.org/pdfiin/2016/Hojaderutaparainstituciones-7.3.pdf

Instituto Interamericano del Niño, la Niña y Adolescentes de la Organización de los Estados Americanos. (2016). Niños, niñas y adolescentes migrantes. Relevamiento de protocolos existentes: Costa Rica, El Salvador, Guatemala, Honduras y México. Recuperado de http://www.iin.oas.org/pdfiin/2016/publicaciones/Relevamiento_Protocolos_Migrantes.pdf

Ley No. 287. Código de la Niñez y la Adolescencia. Publicado en La Gaceta Diario Oficial No. 97 del 27 de mayo de 1998. Nicaragua.

Ley No. 761. Ley General de Migración y Extranjería. Publicada en La Gaceta Diario Oficial No. 125 y 126 del o6 y 07 de julio de 2011. Nicaragua.

Ley No. 7739. Código de la Niñez y la Adolescencia. Publicada en La Gaceta Diario Oficial No. 26 del o6 de febrero de 1998. Costa Rica.

Ley No. 8487. Ley de Migración y Extranjería. Publicada en La Gaceta Diario Oficial No. 170 del 01 de septiembre de 2009. Costa Rica.

Lineamientos Generales para la Atención de Niños, Niñas y Adolescentes Migrantes No Acompañados en casos de Repatriación. 9 de julio de 2009. Recuperado de https://www.corteidh.or.cr/sitios/Observaciones/11/Anexo24.pdf 


\section{LA PROTECCIÓN ESPECIAL Y EL INTERÉS SUPERIOR DE LA NIÑEZ MIGRANTE NO ACOMPAÑNADA EN LOS \\ PROCEDIMIENTOS MIGRATORIOS EN CENTROAMÉRICA: ANÁLISIS LEGISLATIVO}

Memorándum de Entendimiento entre los gobiernos de los Estados Unidos Mexicanos, de la República de El Salvador, de la República de Guatemala, de la República de Honduras y de la República de Nicaragua. 15 de diciembre de 2011. Recuperado de https://www.sica.int/busqueda/busqueda_archivo.aspx?Archivo=memo_ 96645_1_10092015.pdf

Observación General No. 6 "Trato de los menores no acompañados y separados de su familia fuera de su país de origen”, del Comité de los Derechos del Niño. 1 de septiembre de 2006. Recuperado de https://www.acnur.org/fileadmin/Documentos/BDL/2005/3886.pdf

Organización de las Naciones Unidas. (2015). Declaración Universal de los Derechos Humanos (Edición Ilustrada). Recuperado de https://www.un.org/es/documents/udhr/UDHR_booklet_SP_web.pdf

Organización Internacional para las Migraciones. (2017). Derechos humanos de la niñez migrante. Recuperado de http://www.ippdh.mercosur.int/wpcontent/uploads/2017/o2/Derechos-Humanos-de-la-Ninez-Migrante.pdf

Ortega Velázquez, E. (2015). Los niños migrantes irregulares y sus derechos humanos en la práctica europea y americana: Entre el control y la protección irregular. Boletín Mexicano de Derecho Comparado, (142). Recuperado de http://dx.doi.org/10.22201/iij.24484873e.2015.142.4919

Piedra Quesada, V. (Comp.). (2017). Constitución Política de Costa Rica. Editorial Digital de la Imprenta Nacional. Recuperado de https://www.imprentanacional.go.cr/editorialdigital/libros/textos\%20jur idicos/constitucion_politica_digital_edincr.pdf 


\section{LA PROTECCIÓN ESPECIAL Y EL INTERÉS SUPERIOR DE}

LA NIÑEZ MIGRANTE NO ACOMPAÑADA EN LOS

PROCEDIMIENTOS MIGRATORIOS EN CENTROAMÉRICA: ANÁLISIS LEGISLATIVO

Rivas L., E. (2015). La evolución del interés superior del niño: Hacia una evaluación y determinación objetiva. (Tesis de pregrado). Universidad de Chile, Santiago de Chile.

UNICEF. (2020). Migración de niñas, niños y adolescentes. Recuperado de https://www.unicef.org/mexico/migraci\%C3\%B3n-de-ni\%C3\%B1asni\%C3\%B1os-y-adolescentes 